\title{
External Snapping Hip Diagnosis; Making complex simple
}

\author{
Elalfy M Mohamed ${ }^{1 *}$ and Ahmed Zaghloul ${ }^{2}$ \\ ${ }^{1}$ Assistant Lecturer of Orthopedic Surgery, Faculty of Medicine, Mansoura University, Egypt \\ ${ }^{2}$ Lecturer of Orthopedic Surgery, Faculty of Medicine, Mansoura University, Egypt
}

Submission: October 06, 2020; Published: January 15, 2021

*Corresponding author: Elalfy M Mohamed, Assistant Lecturer of Orthopedic Surgery, Faculty of Medicine, Mansoura University, Egypt

Abstract

Introduction: The external snapping hip syndrome is a condition characterized by palpable and or audible click over the lateral aspect of the hip region occurring with movement and may be associated with pain.

Discussion: Extra-articular snapping is divided into external and internal types. The diagnosis of External snapping hip is usually made from clinical examination; however, imaging has been used to rule out other pathologies, to confirm the involved structures, and to investigate tissue change. Sonographic investigation of External snapping hip may not be needed if the diagnosis is clinically obvious. However, sonography should be performed when clinical diagnosis is uncertain because an extraarticular cause can be mistaken for an intraarticular one. Other imaging modalities such as MRI imaging could be used when sonographic findings are negative.

Conclusion: Knowledge on external snapping hip, related pathomechanics and possible complaints allows orthopedic surgeons to diagnose this syndrome and contribute to prompt treatment.

\section{Introduction}

Snapping hip syndrome is characterized by an audible, visible, or palpable snap produced during motion of the hip and/ or a snapping sensation with or without pain. This condition was first reported by Perrin in 1859 and coined by [1] however, in 1995, Allen introduced the term "coxa saltans" to differentiate the causes. [1] The etiology of snapping hip is anatomically divided into intra- and extra-articular causes, with extra-articular snapping being further subdivided into external and internal types. The most common form of coxa saltans is the external extra-articular variety (Coxa Saltans Externa).

\section{Epidemiology}

The incidence and prevalence of this syndrome in the general population is not clear [2], although it is usually found in athletes and dancers, with a reported frequency of up to $62 \%$ in young women [3], and in an asymptomatic manner in between 5\% to $10 \%$ of the population [4]. Affected people visit their doctor because they have difficulty performing common activities such as running, climbing stairs, lifting heavy objects, and even, in some cases, walking. The physical examination is characterized by the reproduction of the noise or palpation of the snap during triggering maneuvers: hip flexion and extension. However, a true prevalence is likely underestimated partly due to the difficulty in the clinical diagnosis and the lack of a standard imaging work-up protocol [4].

\section{Anatomy}

In the external form, the snapping occurs lateral to the hip joint, over the region of the greater trochanter, and is usually attributed to movement of the iliotibial band (Maissiat's band) over the greater trochanter (Figure 1). The iliotibial band (ITB) has two major muscular components: the tensor fascia lata and the gluteus maximus $[5,6,7]$. The ITB is a band of thick connective tissue that runs along the lateral aspect of the thigh. It is a continuation of the tensor fascia lata, which arises from the outer lip of the iliac crest, the anterior superior iliac spine, and the deep surface of the fascia lata and inserts between the two layers of the iliotibial tract (one third of the way down the thigh). The main function of this muscle is to produce the extension and lateral rotation of the leg on the knee joint. Additionally, it contributes to the movements 
of the thigh, acting as a relatively weak abductor and medial rotator on the hip joint $[8,9,10]$. The gluteus maximus muscle originates from several sites: the posterolateral aspect of the sacrum and coccyx, the Sacro tuberous ligament, gluteal surface of ilium (behind the posterior gluteal line), thoracolumbar fascia and gluteal aponeurosis. The muscle fibers take an inferolateral course, converging towards the femur. The most superficial threequarters of the muscle form a tendinous lamina that inserts between the two layers of the fascia lata, thus contributing to the formation of the iliotibial tract. The remaining deep one-quarter of the muscle inserts to the gluteal tuberosity of femur via a broad aponeurosis. The main functions of the gluteus maximus muscle are the extension and external rotation of the thigh at the hip joint. Additionally, its superior part can produce thigh abduction, while the inferior part causes the thigh adduction $[8,10]$.

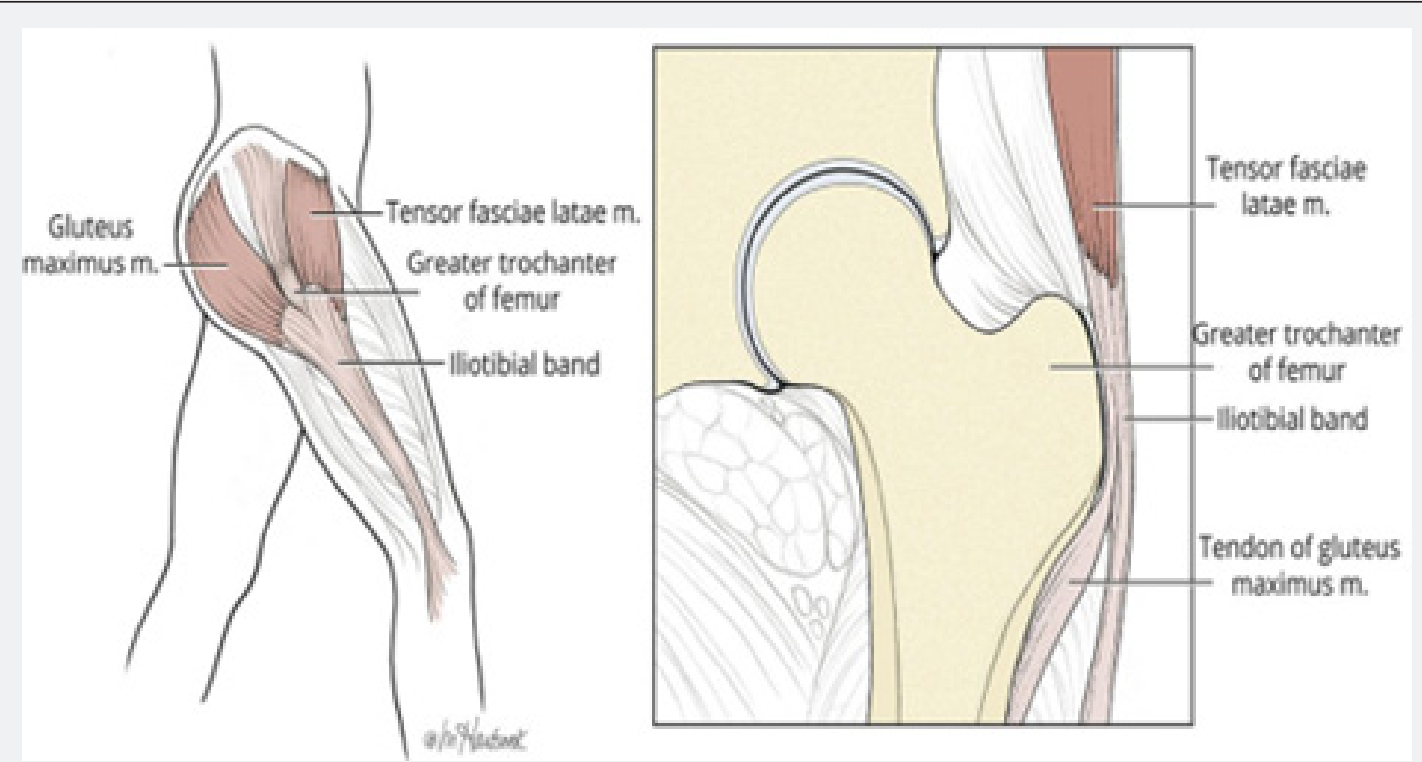

Figure 1: External snapping hip occurs lateral to the hip joint and is attributed to the abrupt movement of the iliotibial band across the greater trochanter.

\section{Aetiology}

External snapping hip syndrome is associated with repetitive physical activities or overuse of anatomical structures related to IBT movements. Some intrinsic risk factors have been identified, such as the narrowing of the bi-iliac distance, increased distance between major trochanters, prominence of the greater trochanter, and fibrosis of the iliotibial band secondary to multiple intramuscular injections [11-13]. Larsen and Johansen reported that patients with external snapping hip had a smaller median femoral neck shaft angle than did controls of a similar mean age. The decreased neck shaft angle, or coxa vara, results in shorter moment arms for the gluteus medius and minimus, making those muscles less efficient abductors. Also, coxa vara may increase stresses on the ITB and lead to external snapping [14]. Additionally, prior surgeries have been identified as a factor in the development of snapping hip. For instance, external snapping has been reported following total hip arthroplasty mainly due to the prominence of the greater trochanter, lateral placement of the prosthetic cup, or reduction in the femoral neck angle [15]. Also, knee reconstruction procedures that use a portion of the ITB have been linked to the development of external snapping hip $[7,16]$.

\section{Pathomechanics}

The most common form of coxa saltans is the external extraarticular variety which involves either the posterior iliotibial band or the anterior aspect of the gluteus maximus as they travel over the greater trochanter during hip flexion and extension or internal and external rotation. Most frequently during flexion, external rotation, and abduction $[2,17,18]$. Usually, thickened portions of the posterior iliotibial band or anterior gluteus maximus tendons snap over the greater trochanter causing the catching or "giving way" sensation and inflammation of the trochanteric bursa eliciting pain. Due to the distinct anatomic location and often visible snapping, coxa saltans externa is often easier to diagnose. Coxa saltans externa can be one of the causes of greater trochanteric pain syndrome, which also includes greater trochanteric bursitis and strains or tendonopathy of the hip abductor mechanism. However, many patients can present with a snapping hip without pain [19]. Whereas external snapping hip is usually due to the ITB, snapping of the gluteus maximus muscle itself has been noted $[20,21]$. A combination of defects is also possible; for example, thickening of both the posterior iliotibial band and anterior gluteus maximus, which snap over the greater 
trochanter at the same time, further accentuates the snapping sound $[22,23]$.

\section{History and Clinical Examination}

A careful history and physical examination will often elicit the correct diagnosis of coxa saltans and determine the correct anatomic region (external, internal, or intra-articular). The patient's description of their snapping will often direct the examiner to the region of interest. Aside from reporting the snap, patients with external snapping hip often describe a sensation of the hip subluxing or dislocating. This sensation has been termed pseudo subluxation [24] and may be visually appreciated as a slight jerking movement [25]. Patients with external snapping hip may report difficulty climbing stairs, running, backpacking, carrying heavy loads, or playing golf [6]. Generally, one of the most important diagnostic indicators of snapping hip is the reproduction of the audible or palpable snap and its concurrence with pain. The movement to reproduce the symptom is somewhat dependent on the type of snapping hip. In external snapping hip, the patient is positioned on lateral decubitus on the examination table, with the affected hip upward, and the Ober test is used to evaluate iliotibial band tightness. The snap may be reproduced by the active flexion followed by passive extension and abduction of the hip. Yen et al. described the hula-hoop test. With the patient is standing position, the hula-hoop test consists in adduction with circumduction of the affected hip. If the circumduction results in a snap over the greater trochanter, the test is positive for external snapping hip. The modified FABER (flexion, abduction and external rotation) test usually cause discomfort to the patient [26].

\section{Imagenological (Radiological) Evaluation}

The diagnosis of coxa saltans externa can be readily made clinically. The snapping of the IT band over the greater trochanter is visible and often demonstrated by the patient [18]. However, imaging has been used to rule out other pathologies, to confirm the involved structures, and to investigate tissue changes. In patients with extra-articular snapping hip, Anteroposterior radiograph of the pelvis and cross table view of the hip are important to study the anatomy of the hip joint. Plain radiographs are most often normal but are helpful to rule out other pathologies [25,27]. A small femoral neck angle (coxa vara) [15] or developmental dysplasia [28] may contribute to snapping hip. Magnetic resonance imaging has been used to detect pathologic soft tissue changes in the involved tendon and bursa because of its high sensitivity and panoramic view. In patients with External snapping hip, a thickened IT band and focal thickening of the anterior edge of the gluteus maximus muscle could be seen on MRI (Figure 2). Axial T1-weighted images best demonstrate the thickening $[6,13]$.

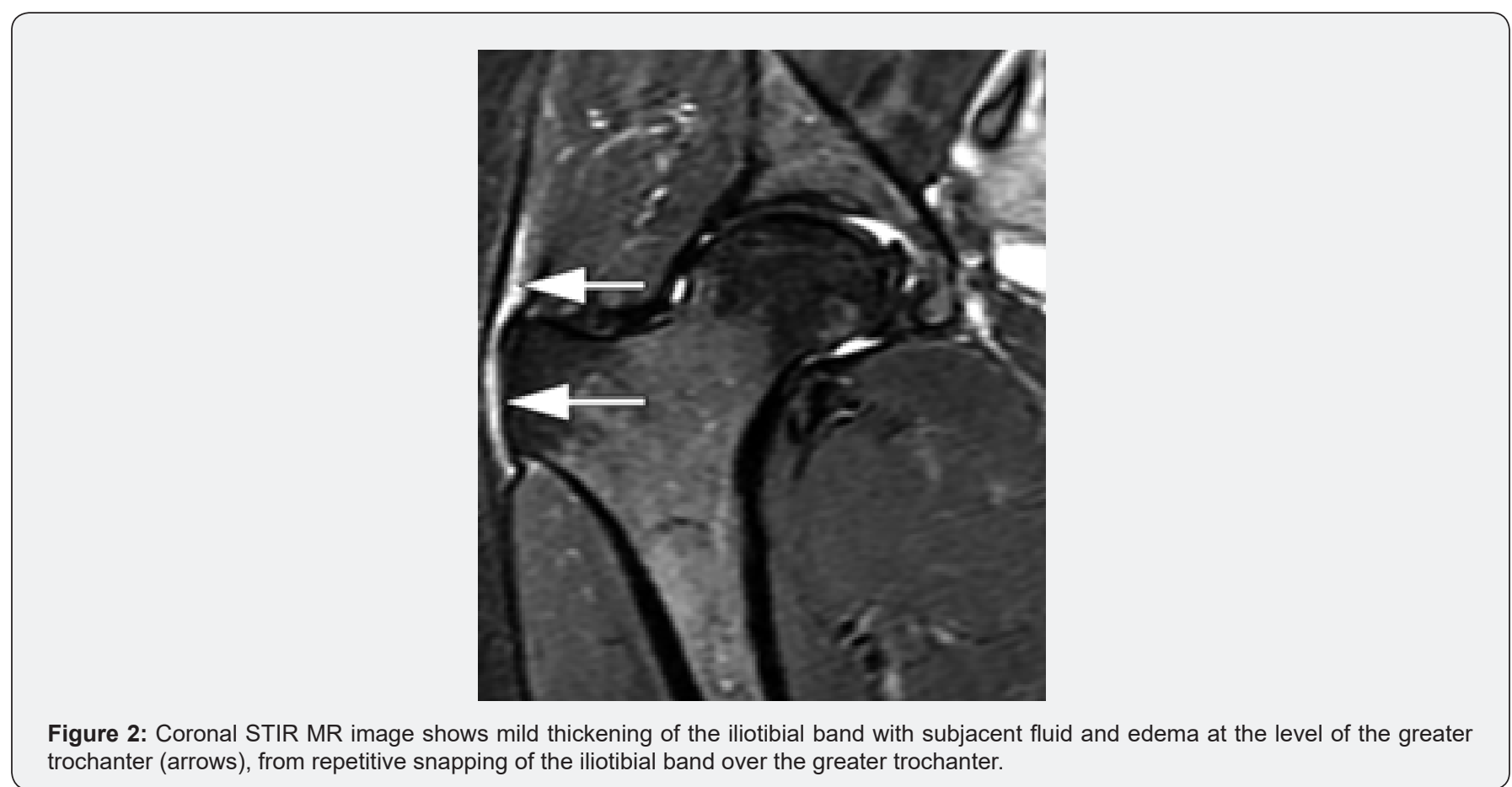

Hyperintense greater trochanteric bursal inflammation or a fluid collection may also be visualized on $\mathrm{T}_{2}$; however, these findings are non-specific and the correlation with the clinical examination is important. Post-contrast imaging can show peritendinous enhancement of involved structures. A small case series correlated atrophy of the gluteus maximus muscle on MRI with external snapping hip. The authors hypothesized that this finding could be due to gait changes to avoid pain. Finally, MRI is also useful to exclude other extra or intra-articular hip abnormalities [29]. Ultrasound has become one of the most 
commonly used tools for snapping hip. Ultrasound can detect bursitis, tendinitis, and synovitis [5] Dynamic ultrasound can detect abrupt movement of the involved tendon (Figure 3) [30-
33]. With external snapping hip, abrupt anterior movement of the ITB or gluteus maximus may occur as the hip is moved from extension to flexion or flexion to extension [34-35].

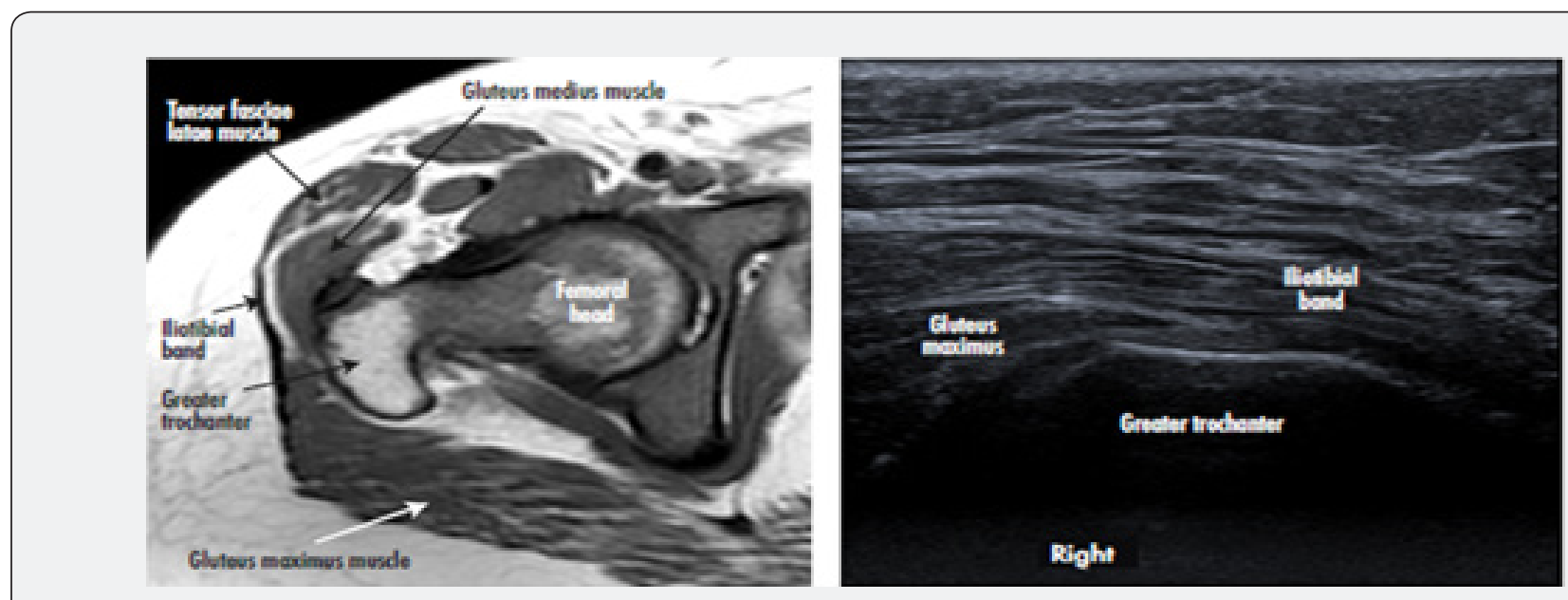

Figure 3: Magnetic resonance and ultrasound (cross-sectional plane) of the right hip of an asymptomatic patient, where the relationship between the iliotibial band, the tendon of the gluteus maximus and the greater trochanter is evident.

The linear transducer (9-12 MHz) is placed transversely over the greater trochanter, and the patient is asked to flex and externally rotate the hip: the abrupt snapping tendon during hip motion can be detected $[5,19]$. But there is still no consensus to determine diagnostic parameters [2,30].

\section{Summary}

Snapping of the hip may have intra- or extra-articular causes or both. Coxa saltans externa is the most frequent type commonly caused laterally by the ITB flipping over the greater trochanter. Multiple factors are involved in development of coxa saltans externa e.g., coxa vara, fibrosis of the iliotibial band and prior hip surgeries. Provocative tests in clinical examination and Dynamic ultrasound are the most useful tools in diagnosis.

\section{References}

1. Nunziata A, Blumenfeld I (1951) Snapping hip; note on a variety Prensa medica argentina 38(32): 1997-2001.

2. Potalivo G, Bugiantella W (2017) Snapping hip syndrome: systematic review of surgical treatment. Hip Int 27(2): 111-121.

3. Lee KS, Rosas HG, Phancao JP (2013) Snapping hip: imaging and treatment. Semin Musculoskelet Radiol 17(3):286-94.

4. Lewis CL (2010) Extra-articular snapping hip: a literature review. Sports health 2(3): 186-190.]

5. Pelsser V, Cardinal É, Hobden R, Aubin B, Lafortune M, et al. (2001) Extraarticular snapping hip: sonographic findings. AJR Am J Roentgenol 176(1): 67-73.

6. Provencher MT, Hofmeister EP, Muldoon MP (2004) The surgical treatment of external coxa saltans (the snapping hip) by Z-plasty of the iliotibial band. Am J Sports Med 32(2): 470-476.

7. Satku K, Chia J, Kumar VP (1990) Snapping hip an unusual cause. J Bone Joint Surg Br 72(1): 150-151.
8. Netter FH (2014) Atlas of human anatomy, Professional Edition E-Book: including Netter Reference. com Access with full downloadable image Bank. Elsevier Health Sciences'

9. Chummy SS (2006) Last's Anatomy Regional and applied. English Language Book Society, Churchill Livingstone 68: 75.

10. Drake R, Vogl AW, Mitchell AW (2009) Gray's Anatomy for Students E-Book. Elsevier Health Sciences.]

11. Krishnamurthy G, Connolly BL, Narayanan U, Babyn PS (2007) Imaging findings in external snapping hip syndrome. Pediatr Radiol 37(12): 1272-1274!

12. Johnston CA, Wiley JP, Lindsay DM, Wiseman DA (1998) Iliopsoas bursitis and tendinitis. Sports Med 25(4): 271-283.

13. Choi JE, Sung MS, Lee KH, Lee BY, Park JM, et al. (2010) External snapping hip syndrome: emphasis on the MR imaging. Journal of the Korean Society of Radiology 62(2): 185-190?

14. Larsen E, Johansen J (1986) Snapping hip. Acta Orthopaedica Scandinavica 57(2): 168-170.

15. Larsen EILIF, Gebuhr P (1988) Snapping hip after total hip replacement. A report of four cases. J Bone Joint Surg Am 70(6): 919-920.

16. Lewis CL (2010) Extra-articular snapping hip: a literature review. Sports health 2(3): 186-190.

17. Flato R, Passanante GJ, Skalski MR, Patel DB, White EA, et al. (2017) The iliotibial tract: imaging, anatomy, injuries, and other pathology. Skeletal Radiol 46(5): 605-622.]

18. Choi YS, Lee SM, Song BY, Paik SH, Yoon YK (2002) Dynamic sonography of external snapping hip syndrome. J Ultrasound Med 21(7): 753-758.

19. Winston P, Awan R, Cassidy JD, Bleakney RK (2007) Clinical examination and ultrasound of self-reported snapping hip syndrome in elite ballet dancers. Am J Sports Med 35(1): 118-126.

20. Brignall CG, Brown RM, Stainsby GD (1993) Fibrosis of the gluteus maximus as a cause of snapping hip. A case report. J Bone Joint Surg Am 75(6): 909-910.] 
21. Pelsser V, Cardinal É, Hobden R, Aubin B, Lafortune M, et al. (2001) Extraarticular snapping hip: sonographic findings. American journal of roentgenology 176(1); 67-73.

22. Beals RK (1993) Orthopedics: Painful Snapping Hip in Young Adults. West J Med 159(4): 481-482.

23. Binnie JF (1913) V Snapping hip (Hanche a Ressort; Schnellende Hufte. Ann Surg 58(1): 59-66.

24. Zini R, Panascì M (2017) Extra-articular Hip Pathology. In Groin Pain Syndrome Springer pp. 79-86.

25. Winston P, Awan R, Cassidy JD, Bleakney RK (2007) Clinical examination and ultrasound of self-reported snapping hip syndrome in elite ballet dancers. Am J Sports Med 35(1): 118-126.

26. Yen YM, Lewis CL, Kim YJ (2015) Understanding and treating the snapping hip. Sports medicine and arthroscopy review. Sports Med Arthrosc Rev 23(4): 194-199.

27. Allen WC, Cope R (1995) Coxa saltans: the snapping hip revisited. JAAOS-Journal of the American Academy of Orthopedic Surgeons 3(5): 303-308.

28. Provencher MT, Hofmeister EP, Muldoon MP (2004) The surgical treatment of external coxa saltans (the snapping hip) by Z-plasty of the iliotibial band. The American journal of sports medicine 32(2): 470476.
29. Lewis CL (2010) Extra-articular snapping hip: a literature review. Sports health, 2(3): 186-190.

30. Teitz CC, Garrett WE, Miniaci A, Lee MH, Mann RA, et al. (1997) Instructional course lectures, the american academy of orthopaedic surgeons-tendon problems in athletic individuals. JBJS 79(1): 138-152.

31. Gilbert DL, Espay AJ, Wu SW (2018) Coxa saltans misdiagnosed as functional gait disorder: Two cases. Neurology 91(6): 276-277.

32. Hegazi TM, Belair JA, Mc Carthy EJ, Roedl JB, Morrison WB, et al. (2016) Sports injuries about the hip: what the radiologist should know. Radiographics 36(6): 1717-1745.

33. Donoso DIC, Calvo Páramo E, Medina-Ramírez RD (2019) Imagenological findings of external snapping hip syndrome. Case reports 5(2): 123-131.

34. Willett GM, Keim SA, Shostrom VK, Lomneth CS (2016) An anatomic investigation of the Ober test. Am J Sports Med 44(3): 696-701.

35. Kendall F, Mc Creary E, Provance P, Rodgers M, Romani W, et al. (2005) Testing and function with Posture and Pain. New Lippinicott Williams \& Wilkins, New York, USA.

\section{Your next submission with Juniper Publishers will reach you the below assets}

- Quality Editorial service

- Swift Peer Review

- Reprints availability

- E-prints Service

- Manuscript Podcast for convenient understanding

- Global attainment for your research

- Manuscript accessibility in different formats

( Pdf, E-pub, Full Text, Audio)

- Unceasing customer service

Track the below URL for one-step submission https://juniperpublishers.com/online-submission.php 